\title{
Reverse Launch Abort System Parachute Architecture Trade Study
}

\author{
Daniel K. Litton ${ }^{1}$ \\ NASA Langley Research Center, Hampton, VA, 23681 \\ Stephen A. O'Keefe ${ }^{2}$ \\ Analytical Mechanics Associates, Hampton, VA, 23666 \\ and \\ Richard G. Winski ${ }^{3}$ \\ Binera, Yorktown, VA, 23693
}

\begin{abstract}
This study investigated a potential Launch Abort System (LAS) Concept of Operations and abort parachute architecture. The purpose of the study was to look at the concept of jettisoning the LAS tower forward (Reverse LAS or RLAS) into the free-stream flow rather than after reorienting to a heatshield forward orientation. A hypothesized benefit was that due to the compressed timeline the dynamic pressure at main line stretch would be substantially less. This would enable the entry parachutes to be designed and sized based on entry loading conditions rather than the current stressing case of a Pad Abort. Ultimately, concerns about the highly dynamic reorientation of the $\mathrm{CM}$ via parachutes, and the additional requirement of a triple bridle attachment for the RLAS parachute system, overshadowed the potential benefits and ended this effort.
\end{abstract}

\section{Introduction and Background}

$\mathrm{T}$ HE Integrated Design Assessment Team (IDAT) was commissioned to ensure that the design of the parachutes and the forward bay volume of the crew module for the Orion Crew Exploration Vehicle (CEV) Launch Abort System closed. The existing parachute architecture uses the same parachutes for Command Module (CM) atmospheric re-entry and launch vehicle aborts. The IDAT study looked at decoupling these parachutes into two separate systems. Decoupling the two sets of parachutes would enable the entry parachute architecture to be driven by entry conditions and not those of a Pad Abort. Pad Aborts are the stressing case for the parachute design due to the timeline and altitude restrictions. Many different possibilities were looked at to decouple the entry and abort parachutes. This paper will focus on jettisoning the Launch Abort System tower earlier in the timeline while using a parachute to reorient the capsule to heatshield forward orientation (Reverse LAS, or RLAS). The baseline concept of operations performed an initial pitch maneuver to separate from the trajectory of the launch vehicle, followed by a coast phase, a phase for reorientation to heatshield forward attitude using the Launch Abort System Attitude Control Motor, and a settling phase prior to jettisoning the tower. Due to the time required for the phases prior to tower jettison, the original concept of operations placed the deployment of drogue and main parachutes at a high dynamic

${ }^{1}$ Aerospace Engineer, AIAA Member.

${ }^{2}$ Project Engineer, AIAA Member.

${ }^{3}$ Senior Aerospace Engineer, AIAA Member.

American Institute of Aeronautics and Astronautics 
pressure. This dynamic pressure is higher than what would be experienced on entry. Thus, Pad Abort is now the driver for the sizing and reefing of the parachutes. By jettisoning the tower earlier during the coast phase and using a parachute to reorient the Crew Module instead, the timeline can be sped up and the main parachutes experiences a much lower dynamic pressure. In this sequence, the reorientation parachute replaces the drogue parachute. The main parachutes used for entry are deployed following the release of the reorientation parachute.

Another benefit of the RLAS is that by jettisoning the tower forward, low dynamics during the coast phase could provide a much cleaner separation between the Crew Module and Launch Abort Tower. A simulation was created in the Program to Optimize Simulated Trajectories II (POST2) to model the dynamics of the RLAS parachute and understand its impacts on the main parachutes. An optimization was performed around the Pad Abort Monte Carlo subsets in order to find the best timing for jettisoning the tower, the best reefing ratio for the reorientation parachute, and the best timing for releasing the reorientation parachute. In certain cases, the reorientation parachute induced large oscillations, which caused the Crew Module to flip after the reorientation parachute was released creating a high potential for loss of crew. Ultimately, concerns about this highly dynamic reorientation of the CM via parachutes, overshadowed the potential benefits and ended this effort.

\section{Models}

The Program to Optimize Simulated Trajectories II (POST2) was used to model the trajectories of the RLAS system. The simulation created was based on the Orion LAS operational model, and included use of the CEV Aerosciences Project (CAP) Aerodynamics Database Version 0.53.1, the ISS 1\& 2 606D mass properties, and Earth GRAM07 atmospheric modeling. A few major/minor modifications to the nominal LAS simulation were required in order to properly model the RLAS design. Minor changes involved modifying versions 10.4, for max drag aborts, and 10.3, for all other aborts, of the controller to prevent reorientation using the Attitude Control Motor (ACM). Major changes included modifying the aerodynamics database for apex forward separation and altering the parachute model in order to be able to model contact between the $\mathrm{CM}$ and its reorientation parachute.

A major concern of the RLAS design was Jettison Motor (JM) plume impingement on the CM and/or any deployed parachutes. In order to mitigate this problem, a gas piston separation mechanism was proposed to replace the JM. The POST2 simulation was used to provide the Lockheed Martin aerosciences community with relative positions and angles of the CM and parachutes with respect to the LAS and JM nozzles for use in CFD analysis. A specified angular deviation from the JM nozzle vectors was used to measure possible JM plume impingement. The same methods and procedures were used for the operational vehicle JM plume risk as well. (CEV-SA-09-023)

Finally a modified version of the Pad Abort 1 (PA-1) smart drogue release was implemented for the CM reorientation parachute. This "smart chute" model ensures the parachute is released when the angular rates are at a minimum, preventing the capsule from flipping before the main parachutes reach line stretch. A coning motion of the CM is a situation in which the algorithm has trouble; if two angular rates are oscillatory and the amplitudes are out of phase, the total angular rate stays nearly constant and the algorithm will not command parachute release and instead the parachute will be released due to a time constraint.

\section{A. Aerodynamics}

For the RLAS study the CEV Aerodynamic Database Application Programming Interface (API) Version 0.53.1 supplied by the NASA CEV CAP team was incorporated into the POST2 simulation to model the aerodynamics of the LAV, Launch Abort Tower (LAT), and CM. There are two important caveats to note about the use of this aerodynamic database for the RLAS study, both with regards to the separation aerodynamics applied to the LAT and $\mathrm{CM}$ base aerodynamic coefficients during the separation of these two bodies.

The first caveat involves the aerodynamics of the LAT separating from the CM. The separation increments for this region are only defined from angles of attack between 140 and 220 degrees, whereas the RLAS simulation experiences values close to zero angle of attack at the moment of separation. According to the CEV Aerodynamic Database Application Programming Interface Users' Guide (Reference 0):

for any input parameters falling outside the database range; the procedure will be to 'hold last value.' This means that the largest input value represented in the table will be used when the input value is greater than the largest table value and the smallest input value represented in the table will be used when the input value is smaller than the smallest table value.

Therefore, for the separation regime experienced by the RLAS configuration the aerodynamic separation increments are holding values equivalent to 140 or 220 degrees angle of attack instead of the actual zero degrees angle of attack. The potential effects of this discrepancy on the results of this study are not fully understood.

The second important caveat deals with the aerodynamics of the CM separating from the LAT. Due to the discrepancy between the observed angle of attack at separation and the values in the aerodynamic database tables, as 
noted above, the aerodynamic separation increments for the CM from the aerodynamic database were discarded. In their place a very rough estimate, provided by the CAP team, was used. Figure 1 shows the preliminary axial force coefficient increment included in this estimate. It should be reiterated that these increments are a quick preliminary estimate, involving several simplifying assumptions, of the actual aerodynamic effects experienced by the CM while in apex forward flight in close proximity to the LAT.

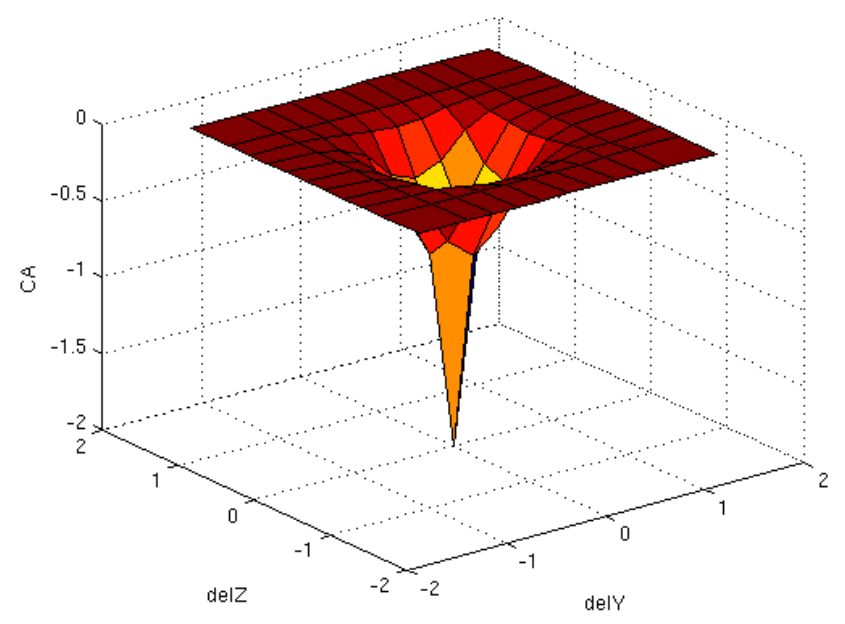

FIGURE 1. Preliminary axial force coefficient increment applied to CM separating from LAT.

In order to complete the simulation analysis of the RLAS concept of operations several parachute sequences are used with varying CONOPS. To better model the dynamics associated with multiple parachutes being deployed at once, each parachute in the simulation is modeled as a separate 6DOF body representing a rigid simplification of the canopy and suspension lines. This body is then connected via a riser line, represented as a tension only spring, to either a triple bridle confluence point or the Crew Module itself based on the particular parachutes being modeled. When multiple parachutes are deployed at once, i.e. three pilot or three main parachutes, a simple compression only spring is used to ensure that the parachutes do not occupy the same physical space.

Throughout the RLAS study several parachute concept of operations were evaluated. These concepts were derived from two main ideas: apex forward LAT jettison and reoriented heat shield forward LAT jettison. The apex forward designs focus on a forward flight jettison of the LAT with either a pre-jettison deployment of additional abort pilot and main parachutes or a post-jettison mortar of a small reorientation parachute followed by mortar deployed pilot parachutes pulling out the main parachutes. The jettison of the LAT is simulated as being completed through the use of the nominal jettison motor and/or a gas piston separation mechanism. Those designs which incorporate a reorientation prior to LAT jettison do so via either the Attitude Control Motor or a small parachute attached to the apex of the LAT, followed by pilot parachutes, deployed by either mortars or static line attachment to the LAT, deploying three main parachutes.

The case that is explored in detail in this document followed the following concept of operations. After aborting from the launch vehicle the LAT is deployed apex forward via six gas pistons. A reefed auxiliary parachute is then mortared from the $\mathrm{CM}$ and allowed to reorient the $\mathrm{CM}$ to a heat shield forward orientation. The auxiliary parachute is fully opened and after several seconds released according to a "smart" algorithm. Three pilot parachutes are then mortared from the CM to deploy the three main parachutes.

\section{B. Reorientation Parachute}

The reorientation parachute is sized to reorient the crew at a rate acceptable by the HSIR requirements. The maximum allowable drag area for the first stage of the reorientation parachute that performs within the HSIR requirements is $62.5 \mathrm{ft}^{2}$ (Reference 4). However, it was found that a drag area of $62.5 \mathrm{ft}^{2}$ is too small to reorient the capsule and arrest the resulting body rates. The large rates brought about by the reorientation forced the use of a second stage of the reorientation parachute to stabilize the CM. The second stage was sized to match the $579 \mathrm{ft}^{2}$ drag area of the Maximum Launch Abort System (MLAS) test vehicle (Reference 5). This value was chosen for this study due to the successful reorientation performed during the MLAS test flight. The difference in the dynamics 
between a parachute with a $236 \mathrm{ft}^{2}$ and a $579 \mathrm{ft}^{2}$ drag area is shown in Figure 2. The smaller parachute does not prevent the initial overshoot and the angle of attack grows to nearly 240 degrees during the reorientation. The larger parachute prevents much of this overshoot and stops the reorientation at 215 degrees.

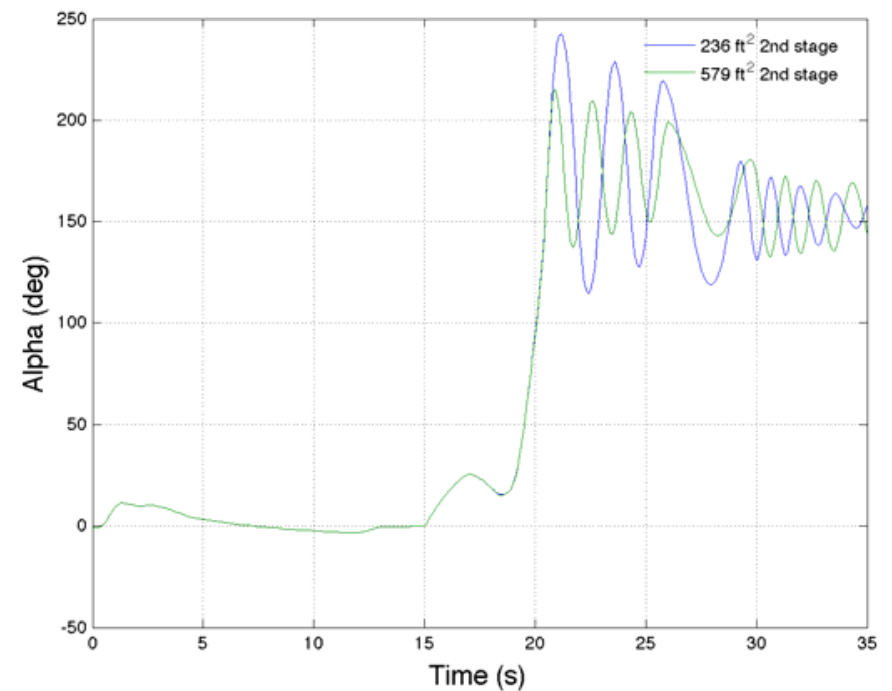

Figure 2. Angle of attack time history for two sizes of reorientation parachute 2 nd stages.

A smart reorientation parachute release, similar to the smart drogue parachute release used in PA-1 (Reference 6), is required due to the high rates induced by reorienting with a parachute. The smart parachute release algorithm stores the pitch, yaw, and roll rates of the CM for the previous 4 seconds at intervals of $0.02 \mathrm{~s}$. The algorithm is turned on a short time (5 seconds for PA-1) after parachute mortar fire and signals release when the rates are increasing and below a percentage of the cumulative average of the previous 4 seconds. If the algorithm does not find suitable conditions by a set time, the algorithm is terminated and the parachute is released.

From initial results it was found that a single attach point would not be sufficient to damp the rates induced by reorientation from a reorientation parachute. Therefore the reorientation parachute was given a triple attach point harness to aide in damping out the dynamics.

\section{Reorientation Parachute Line Contact Force}

Simulation analysis of the RLAS concept of operations has found, as expected, that due to limitations of the point mass models of the LAS project simulations the parachute lines violate reality by passing through the CM. This same problem was encountered during a previous study, which required any attitude drogue parachutes to reorient the CM. In reality, the parachute lines will wrap around the CM, applying forces generated by a flagging parachute at edges such as the CM heat shield shoulder. This problem results in a diminished moment during the reorientation inducing a slower reorientation and associated timeline lag for later event initiation. To correctly model the reorientation a model was generated to simulate that parachute line contact. The three pieces of information required for the reorientation parachute model are:

1. The position of the parachute and confluence fitting in the CM frame of reference.

2. The requirement for contact.

3. The force applied to the CM.

For this initial contact model, the $32.5^{\circ}$ angle of the back shell is used as the requirement for contact between the parachute and CM. Once the parachute is determined to be inside this angle, a force is constrained to be lateral and applied to the CM heat shield shoulder. The force is scaled to the reorientation parachute drag force, proportional to the angle inside the back shell; the further the line is towards the center, the higher the force applied.

\section{Discussion}

\section{A. Effect of Parachute Line Contact Model}


Figure 3 shows the effect of the contact force through the total angle of attack at reorientation. Notice that the reorientation without the model is initially sluggish, taking nearly 1.5 seconds to begin. The cause is the parachute line that is residing inside the CM body producing an almost zero length moment arm. There is a large difference when the model is turned on; the parachute line reaches the back shell but a lateral force is applied to the heat shield shoulder. Immediately the $\mathrm{CM}$ dynamics respond by reorienting. Also on this plot are dispersed cases with the line contact model applied; those cases respond similarly without the lagging reorientation.

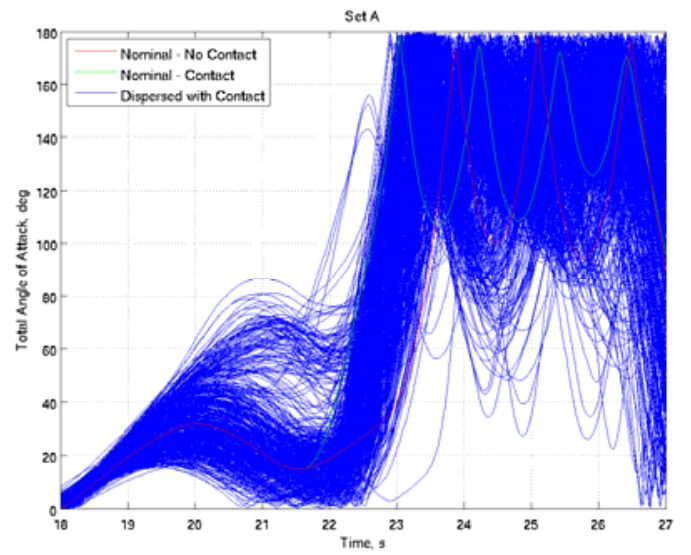

Figure 3. Effect of line contact model on CM total angle of attack.
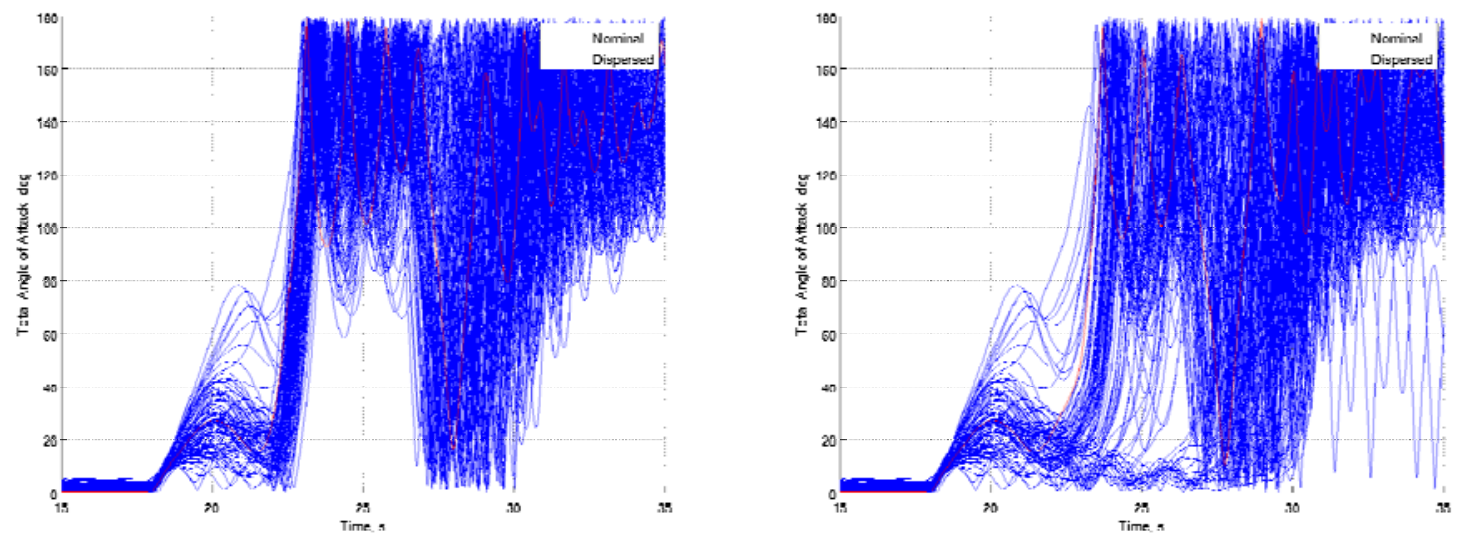

Figure 4. Total angle of attack comparison for cases with and without the line contact model.

As can be seen in Figure 4, the contact model forces the reorientation of all the cases whereas without it, the simulation shows cases that do no reorient after several seconds. In reality, with parachutes line wrapped around the $\mathrm{CM}$, all the cases would reorient or tumble. 

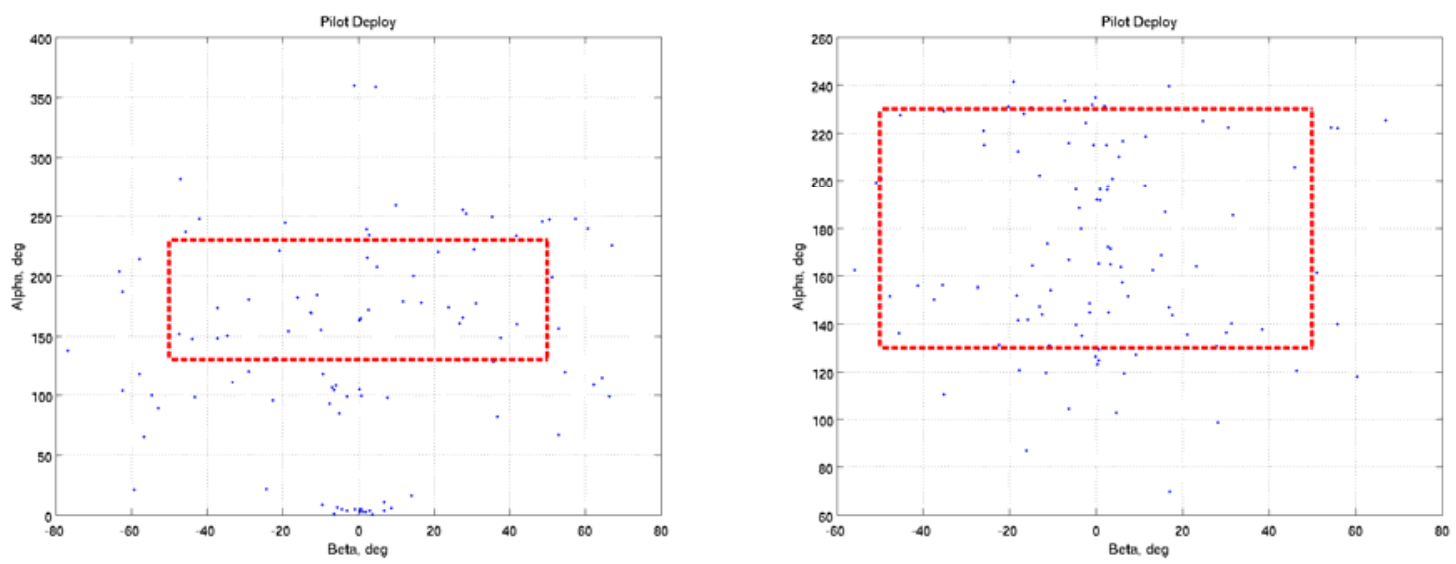

Figure 5. Aerodynamic angles at pilot parachute deployment.

A greater percentage of the cases are pushed back into the requirements boxes as shown in Figures 5 and 6 . Note that only 100 cases were run for this model demonstration.
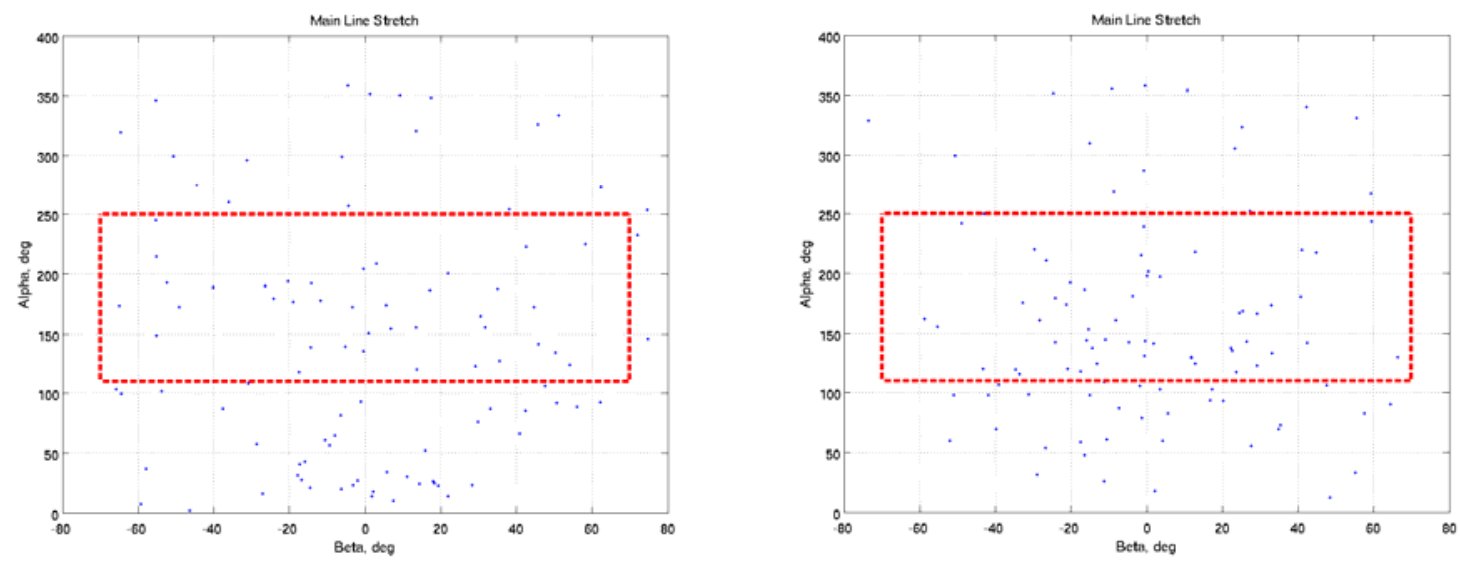

Figure 6. Aerodynamic angles at main parachute line stretch. 

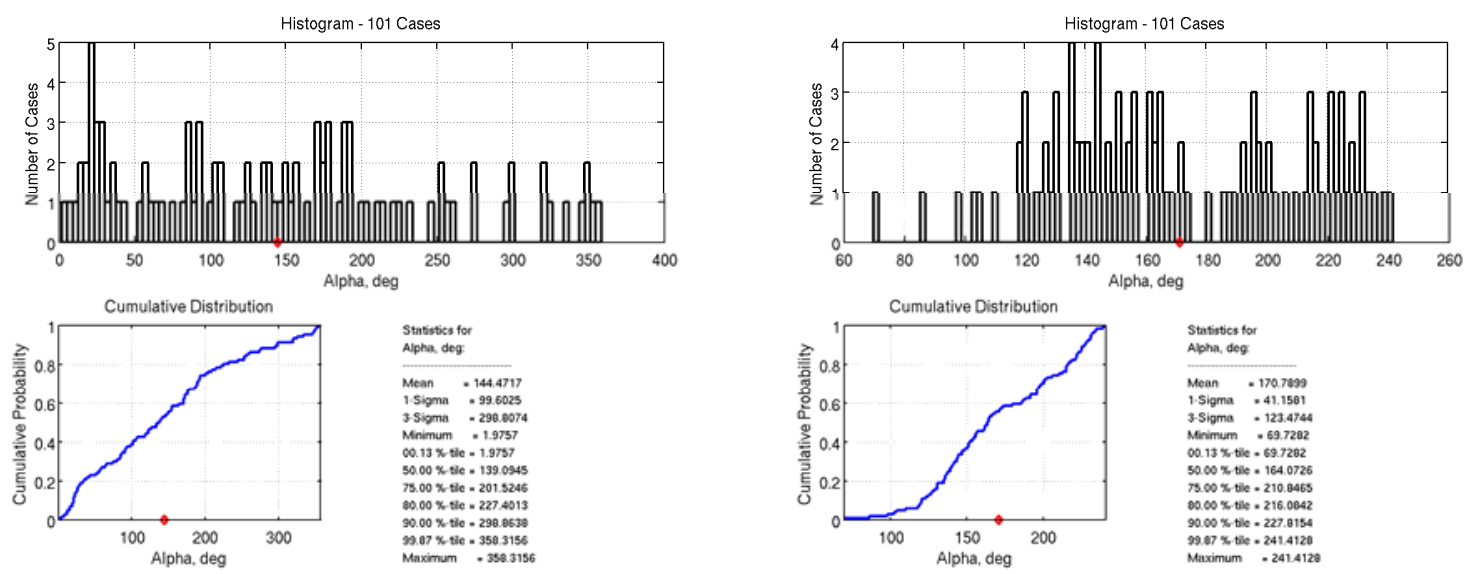

Figure 7. Angle of attack statistics at main parachute line stretch.

The CDF (Cumulative Distribution Function) plots in Figure 7 show that with the contact model more cases have aerodynamic attitudes closer to the nominal simulation results.

\section{B. Launch Abort Tower Separation Thrusters}

Separation thrusters are required for the RLAS design due to possible impingement of Jettison Motor plume on the $\mathrm{CM}$ and/or the reorientation parachute. In order to mitigate this issue, gas piston separation thrusters were placed on the LAT to push the tower away from the CM. An initial design of six 25,000 lbf thrusters was estimated to propel the tower away from the $\mathrm{CM}$ at $34 \mathrm{ft} / \mathrm{s}$ (Reference 7). Results from this study show the thrusters do achieve this separation velocity between the CM and LAT. An example case is shown in Figure 8. The mean value from a Monte Carlo is approximately $39 \mathrm{ft} / \mathrm{s}$, which is an acceptable difference from the estimated value due to the assumptions, such as constant drag on the vehicle, made in the estimate.

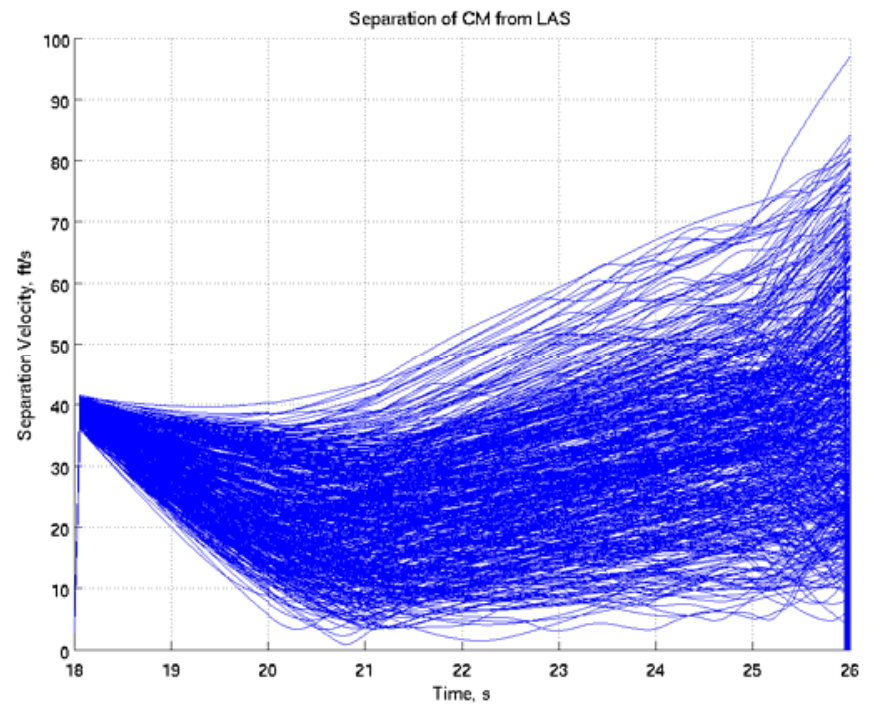

Figure 8. Monte Carlo values for velocity of separation between CM and LAS.

\section{Metrics}


Due to the preliminary nature of this study, the only metrics evaluated include those directly impacted by the switch from heat shield forward deployed parachutes to apex forward deployed parachutes. The metrics looked at are: tumbling between drogue parachute release and main parachute line stretch, CM attitude at main parachute deployment, and in close separation between the CM and the LAT. In addition to these metrics, the CM is required to land in water with at least 10ft of depth. The RLAS trajectories are unchanged from the current operational system until reorientation; therefore structural metrics such as q-alpha-total and CLV separation distance are not discussed. Since the RLAS uses a reorientation parachute instead of the nominal drogue parachutes, the drogue parachute metrics are also excluded. The limits on the metrics considered are included below.

Table 1. Trajectory failure metric limits.

\begin{tabular}{|c|c|}
\hline Metric & Limit \\
\hline $\begin{array}{c}\text { Tumbling between drogue parachute release and main } \\
\text { parachute line stretch }\end{array}$ & Total alpha $\leq 90^{\circ}$ \\
\hline CM aerodynamic angles at main parachute line stretch & $\begin{array}{c}110^{\circ} \leq \text { beta } \leq 250^{\circ} \\
110^{\circ} \leq \text { alpha } \leq 250^{\circ}\end{array}$ \\
\hline CM/LAT lateral separation distance & Not Yet Defined \\
\hline
\end{tabular}

The main concerns with the RLAS design include whether the apex forward separation will reduce the risk of recontact between the CM and the LAT as they separate and whether or not sufficient time exists to damp out the CM body rates caused by the reorientation parachute.

\section{Results}

The RLAS design was simulated at several abort conditions to evaluate its overall performance and feasibility. The results of Monte Carlo analyses performed for pad aborts, aborts at 8,000ft altitude and aborts near Mach 1.0 in the CLV trajectory are summarized in the following sections.

\section{A. Pad Abort}

Aborts from the pad are typically the limiting abort condition due to the constrained timeline. There is very little time to damp out rates after drogue/reorientation parachute deploy due to the lack of altitude achieved. In order to perform a successful pad abort using the RLAS concept of operations a two stage reorientation parachute is required with a smart parachute release algorithm. As was previously mentioned, in order to meet HSIR requirements, the reorientation parachute must have a drag area less than $62.5 \mathrm{ft}^{2}$ (Reference 4). Due to this requirement, a single stage parachute will not generate enough force to damp out the dynamics of the CM. A second stage with a drag area of $579 \mathrm{ft}^{2}$ is required to arrest the dynamics of the CM. In addition to the larger second stage, a smart parachute release is required to prevent flipping of the CM between reorientation parachute release and main parachute line stretch. Since there is not enough time to damp the rates out under the drogue parachutes for a Pad Abort the smart parachute release algorithm attempts to ensure the $\mathrm{CM}$ is released with rates low enough to avoid tumbling before the main parachutes reach line stretch.

An optimization is used to find the best solution within the set of control variables available. The variables used in the optimization are tower jettison time, time on the first stage of the reorientation parachute, time to initiate the smart reorientation release algorithm, maximum time under the reorientation parachute, and the maximum percentage of the mean of the previous four seconds measured rates at smart parachute release. The optimization found the tower needs to be jettisoned at 13.75 seconds and the time on the first stage of the reorientation parachute needs to be 2 seconds. Currently a nominal Pad Abort jettisons the tower much later at 18 seconds. In order to achieve the necessary CM dynamics after reorientation, a lower dynamic pressure is required. Trajectory apogee and minimum dynamic pressure occur at approximately 17-18 seconds; therefore tower jettison needs to occur earlier than currently specified in the operational concept of operations. Setting the tower jettison time to 13.75 seconds causes our reorientation parachute to reach line stretch at 16.75 seconds and second stage disreef to full open at 18.75 seconds, nicely straddling the point of apogee.

Due to the high rates, the optimizer found a value of $65 \%$ as the maximum percentage of the mean of the previous four seconds measured rates at which to release the parachute. The value of $90 \%$ currently in the PA-1 concept of operations is not low enough to prevent the CM from tumbling after the smart parachute release. The 
optimization process found that giving the smart reorientation parachute release algorithm authority to release the parachute between 23.5 seconds and 26.25 seconds gives the lowest risk of tumbling. The final concept of operations determined by optimizer is given in Table 2 .

Table 2. Final parachute timeline for RLAS configuration.

\begin{tabular}{|l|c|}
\hline \multicolumn{1}{|c|}{ Event } & Time (sec) \\
\hline Tower Jettison & 13.75 \\
\hline FBC Jettison & 15.75 \\
\hline Reorientation parachute mortar & 15.75 \\
\hline Reorientation parachute line stretch & 16.75 \\
\hline Reorientation parachute disreef to full open & 18.75 \\
\hline $\begin{array}{l}\text { Reorientation parachute release and pilot parachute } \\
\text { mortar }\end{array}$ & $23.5-26.25$ \\
\hline
\end{tabular}

The total angle of attack time history in Figure 9 shows that for the Monte Carlo performed, the CM reorients nicely and the reorientation parachute begins to stabilize the CM. Once the CM is under the reorientation parachute the CM is forced to trim between 170 and 175 degrees angle of attack due to the reorientation parachute's triple attach point. Initially, the oscillations in total angle of attack are as high as 100 degrees off this trim point, but when the reorientation parachute is released they damp down to 30-40 degrees off of trim. Although this is a large decrease in total angle of attack, 30-40 degrees from trim still causes large moments when the reorientation parachute is released. This is the reason why it is important to have the smart parachute algorithm to pick a good time to release the reorientation parachutes under the least dynamic conditions. The dip in total angle of attack starting at $13.75 \mathrm{~s}$ (tower jettison) is due to the CM free flight trim point of approximately 30 degrees in apex forward flight. The other inflection in the curve around $17 \mathrm{~s}$ is due to the $\mathrm{CM}$ going through apogee and changing quickly.

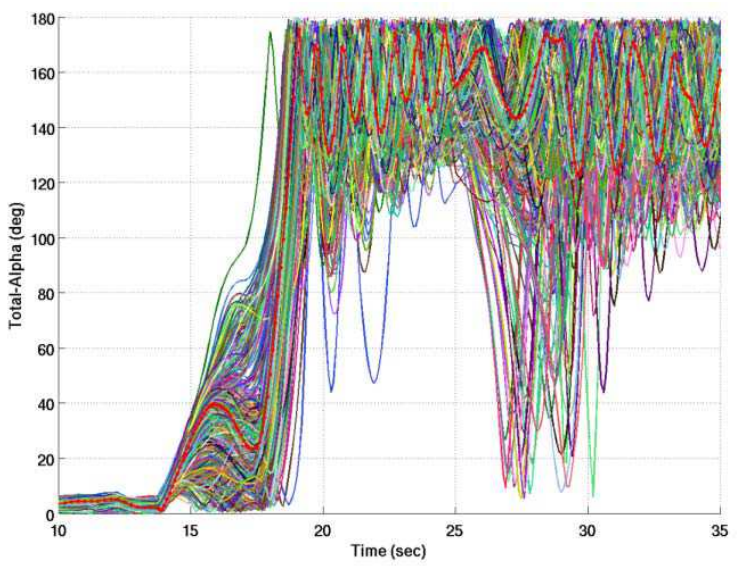

Figure 9. Pad Abort Monte Carlo total angle of attack time histories.

The timeline above, in combination with the larger reorientation parachute and smart parachute release, aides in bringing the failures due to flipping between tower jettison and main parachute line stretch below 5\%. The Pad Abort failure numbers are given in table 3. It is noteworthy that when everything is combined the number of failures is less than $5 \%(88 / 2000)$ as this is the current metric for deciding if the system can successfully abort at a given flight condition.

Table 3. Percentage of failures for 2000 case Pad Abort Monte Carlo.

Metric

Failures 


\begin{tabular}{|l|c|}
\hline $\begin{array}{l}\text { Tumble between drogue parachute release and main parachute line } \\
\text { stretch }\end{array}$ & $3.4 \%$ \\
\hline Angle of attack at main parachute line stretch & $3.3 \%$ \\
\hline Angle of sideslip at main parachute line stretch & $0.15 \%$ \\
\hline Failure to reach 10ft water depth & $0.15 \%$ \\
\hline Total Failures & $\mathbf{4 . 4 \%}$ \\
\hline
\end{tabular}

One of the main focuses of this study is to evaluate separation distance between the LAT and CM. The idea behind the RLAS is to jettison the tower in a very stable (apex forward) condition. Figure 10 depicts the total separation distance between the CM and LAT over the 9 seconds after tower jettison. A major thing to note is the tower initially separates well using the separation thrusters, but after 1.5 seconds the LAT comes back towards the $\mathrm{CM}$. This anomaly is due to the way the aerodynamic data is constructed. Since both vehicles are very dynamic after tower jettison, the angles between the two vehicles change rapidly. Therefore, the two vehicles are no longer axially aligned, the orientation in which they were assumed during construction of the aerodynamics database. The aerodynamic database calculates the separation distance in a coordinate system fixed to one vehicle, thus for example, if one vehicle is rotated 90 degrees from the other the $\mathrm{x}$ separation distance will become small in the frame of measurement and inaccurate aerodynamic coefficients will be applied.

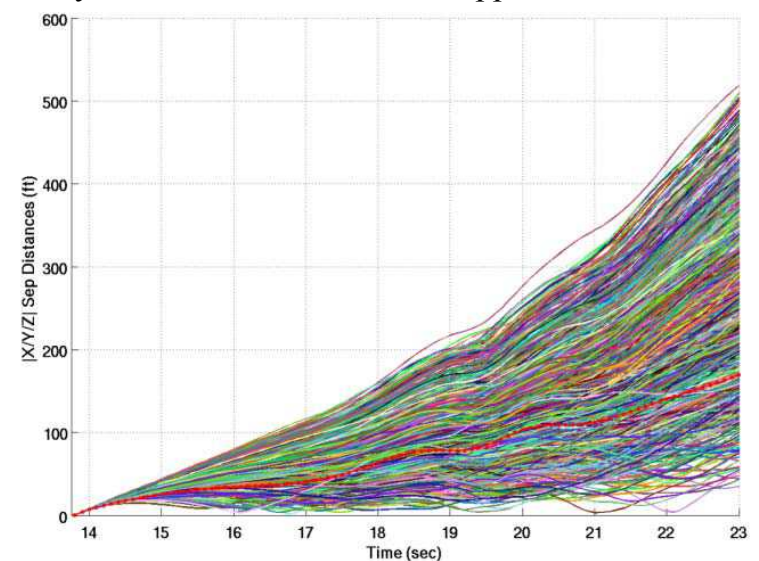

Figure 10. Total separation distance between LAT and CM versus time for a Pad Abort Monte Carlo.

Since neither vehicle has enough time to rotate in the first 0.1-1.5 seconds the in-close separation distances are reliable. Figure 11 shows the close proximity separation distance between the LAT and the CM. It can be seen that there is little lateral movement in the first foot of relative axial separation, which is the period of time with the highest chance of recontact between the LAT and CM. 


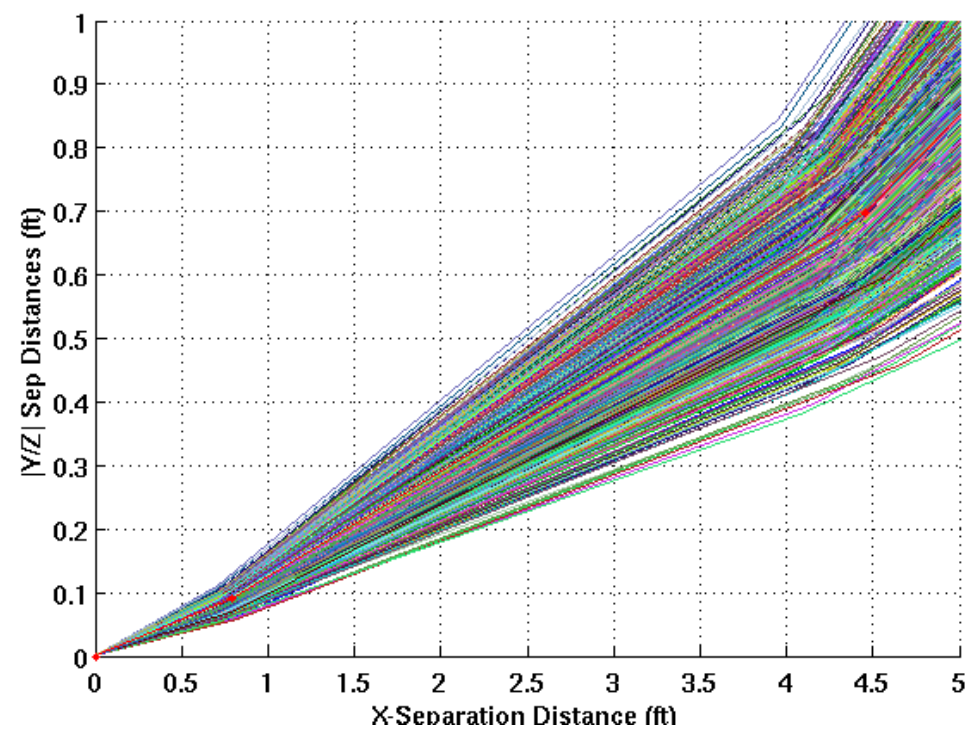

Figure 11. Separation distance between the CM and LAT for a Pad Abort Monte Carlo.

As can be seen in Figure 12 another major benefit of this design is the low dynamic pressure at main parachute line stretch. This lower dynamic pressure is due to a faster reorientation and the use of a larger reorientation parachute as opposed to the current baseline drogue parachutes. While under the current operational drogue parachutes, the CM accelerates for pad aborts, whereas under the reorientation parachute, the CM decelerates, which can be seen from 18-26 seconds. This decrease in velocity and dynamic pressure tremendously aides in reaching main parachute line stretch at a lower dynamic pressure than the current operational concept of operations. The maximum dynamic pressure at main line stretch for this Monte Carlo is less than $70 \mathrm{psf}$. The maximum dynamic pressure on the mains for the current baseline is greater than $85 \mathrm{psf}$. This is a tremendous savings from the current baseline.

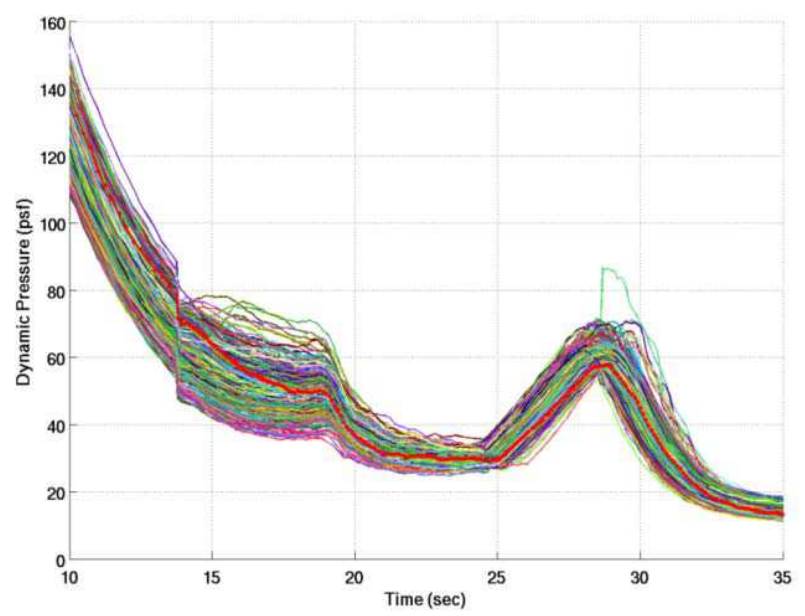

Figure 12. Pad Abort Monte Carlo dynamic pressure time histories.

\section{B. 8000ft Abort}

LAV abort simulations (POST2) are initiated from approximately 8,000 $\mathrm{ft}$ altitude from the TD6-H CLV trajectories (Light/Fast, August, Lunar mission, Open launch window). This Monte Carlo set consists of 2,000 cases 
from abort initiation to CM splashdown/touchdown. No parachute failures are evaluated here. The timeline is not optimized but determined by a short trial and error procedure. The main goal is to enable the reorientation parachute to reorient the $\mathrm{CM}$, but disreef to the full open diameter almost immediately after reorientation is accomplished to allow the larger drag area of the full open parachute to arrest the attitude rates. Since this event would be accomplished through a timer, the time is set in the nominal simulation and the dispersed cases are run to evaluate the effectiveness of this choice in a more general sense.

Table 4. Timeline for 8,000ft abort.

\begin{tabular}{|l|c|}
\hline \multicolumn{1}{|c|}{ Event } & $\begin{array}{c}\text { Time from Abort } \\
\text { Initiation (sec) }\end{array}$ \\
\hline LAS jettison & 18.0 \\
\hline FBC separation & 19.0 \\
\hline $\begin{array}{l}\text { Reorientation } \\
\text { deployment }\end{array}$ & 20.0 \\
\hline Reorientation parachute 2 ${ }^{\text {nd }}$ reef & $\sim 23.1$ \\
\hline Pilot parachute deployment & $\sim 28.4$ \\
\hline Main parachute deployment & $\sim 29.1$ \\
\hline
\end{tabular}

Figure 13 gives a good indication of the altitude range seen around an $8000 \mathrm{ft}$ abort. As evidenced by Figure 14, the disreef to full open on the reorientation parachute occurs nearly simultaneous to the completion of reorientation. Obviously, some cases are more dynamic and result in some flipping. The majority of the cases flip after reorientation parachute release and main parachute line stretch. The smart release algorithm is in use but some cases are too dynamic to satisfy the algorithm's constraints; vehicles are released with non-minimum attitude rates at the maximum time allowed by the algorithm to prevent excessive overall altitude losses. Note again that nothing in these runs has been optimized.

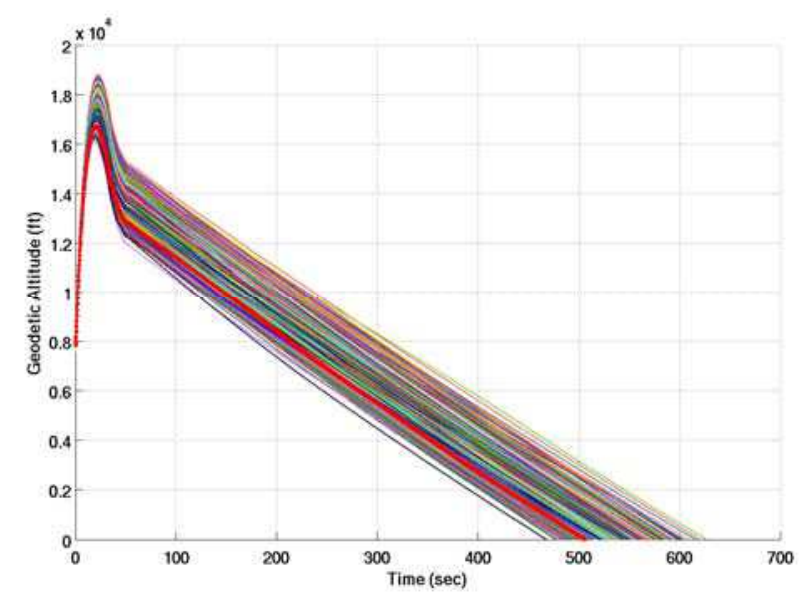

Figure 13. 8,000ft abort Monte Carlo altitude time histories.

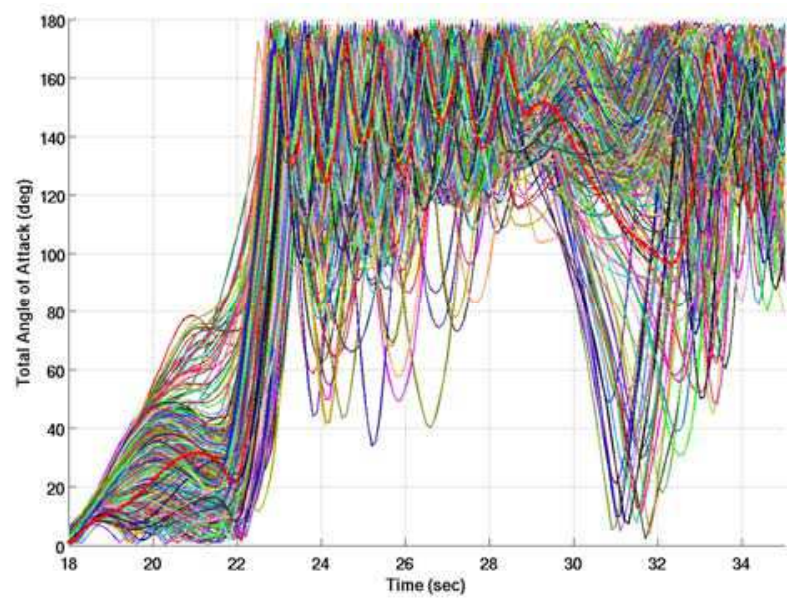

Figure 14. 8,000ft abort Monte Carlo total angle of attack time histories. 


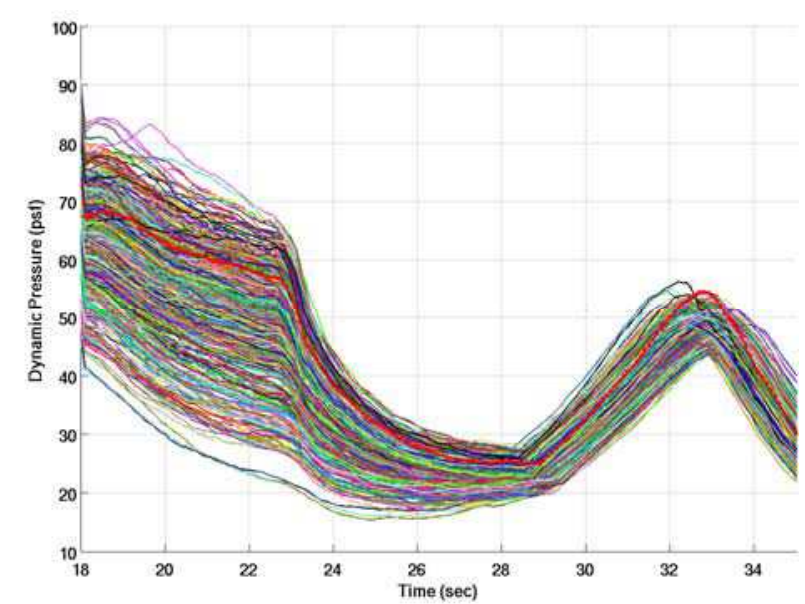

Figure 15. 8,000ft abort Monte Carlo dynamic pressure time histories.

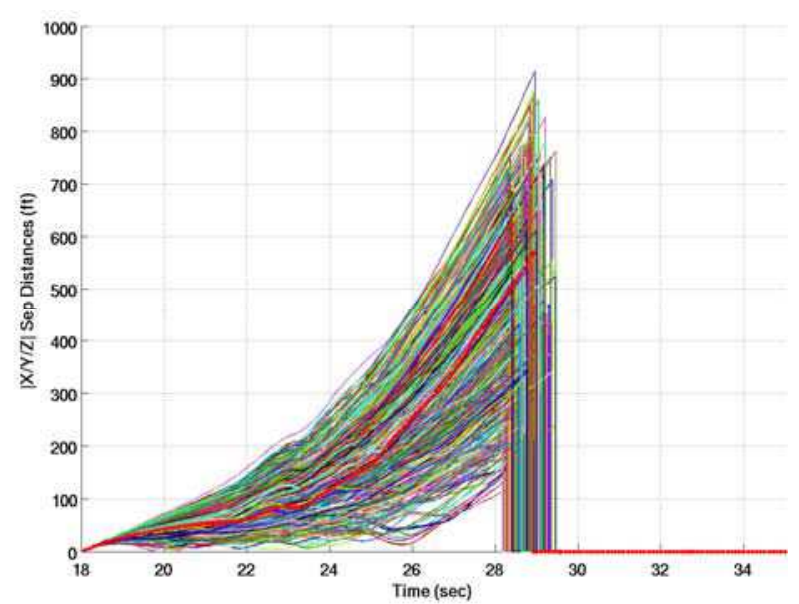

Figure 16. 8,000ft abort Monte Carlo separation distance time histories.

Figure 15 shows one of the greatest benefits of RLAS; the dynamic pressure is low at main parachute line stretch and inflation. This low dynamic pressure, approximately 25 psf lower than the nominal concept of operations, results in much lower parachute line forces. However, some of the cases that flip before main parachute line stretch might be fixed if the dynamic pressure were higher since the capsule is nearly in the more stable heat shield forward orientation at release of the reorientation parachute. Figure 16 shows the separation distance of the LAS and the $\mathrm{CM}$; for the most part the distance meets the requirements but there are a few cases that do not seem to separate. Some of these can be attributed to the separation aerodynamics. Due to the very limited amount of time, the RLAS specific separation aerodynamics did not account for the rotation of the CM with respect to the LAS during separation and caused incorrect aerodynamic coefficient values to be output into the simulation, which worsened the separation distance metric.

Table 5. 8,000ft abort performance metric summary.

\begin{tabular}{|l|c|}
\hline \multicolumn{1}{|c|}{ Metric } & Failures \\
\hline Pre-reorientation tumbling & 0 \\
\hline Aerodynamic loading & 0 \\
\hline Roll rate at reorientation parachute deploy & 0 \\
\hline Mach at reorientation parachute deploy & 0 \\
\hline Qbar at reorientation parachute deploy & 0 \\
\hline$\alpha$ at main parachute deploy & 23 \\
\hline$\beta$ at main parachute deploy & 6 \\
\hline Roll rate at main parachute deploy & 0 \\
\hline Qbar at main parachute deploy & 0 \\
\hline 10ft water depth landing & 243 \\
\hline Vertical landing velocity & 0 \\
\hline Total failures / Total runs & $272 / 2001(13.6 \%)$ \\
\hline
\end{tabular}

Table 5 provides a summary of the performance metrics against which the 8,000ft LAV aborts are compared. The largest contributor to the total number of failures is the $10 \mathrm{ft}$ water depth requirement. The cause is the amount of time on the main parachutes. Many of these failed cases could be eliminated with the use of wind placards. Otherwise, the attitude failures at main parachute deployment are expected due to the dynamic nature of the reorientation parachute. 


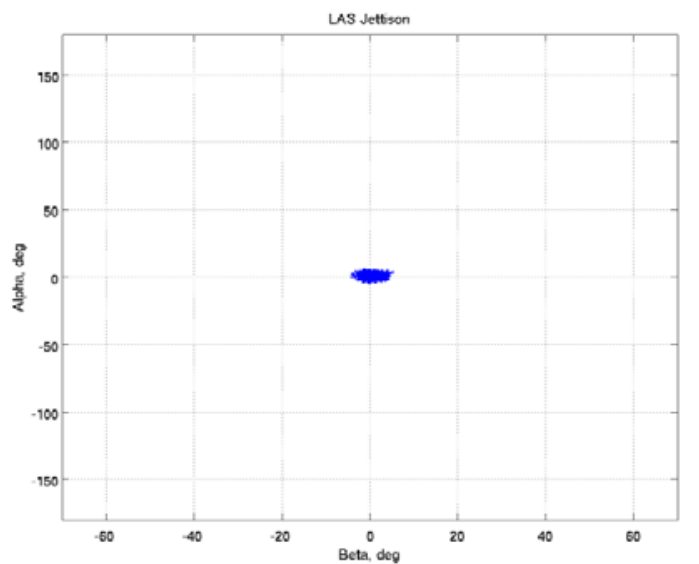

Figure 17. CM aerodynamic angles at LAS jettison for 8,000ft abort Monte Carlo.

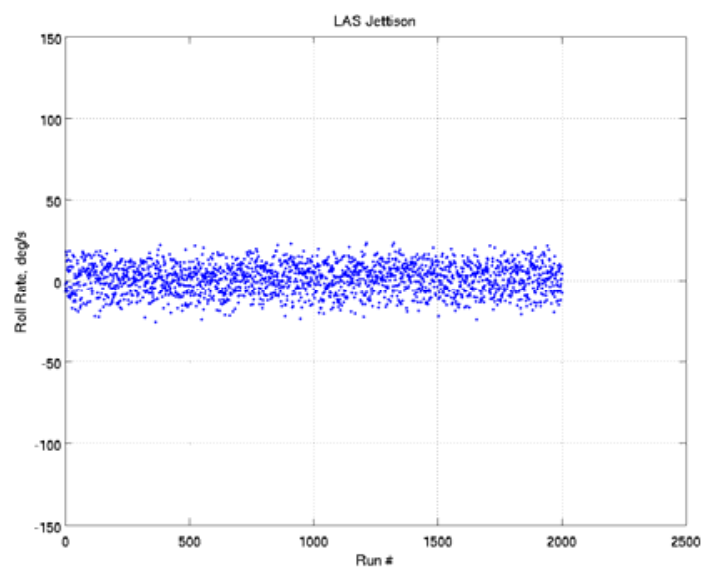

Figure 18. CM roll rate at LAS jettison for $8,000 \mathrm{ft}$ abort Monte Carlo.

One of the benefits of RLAS is the stability of the LAV in its launch orientation. One expectation was that the attitude at LAS jettison would be stable with the aid of the ACM, which is close to underpowered for the reorientation of the baseline concept of operations. Figures 17 and 18 show that the aerodynamic attitude and the roll rate are well behaved.

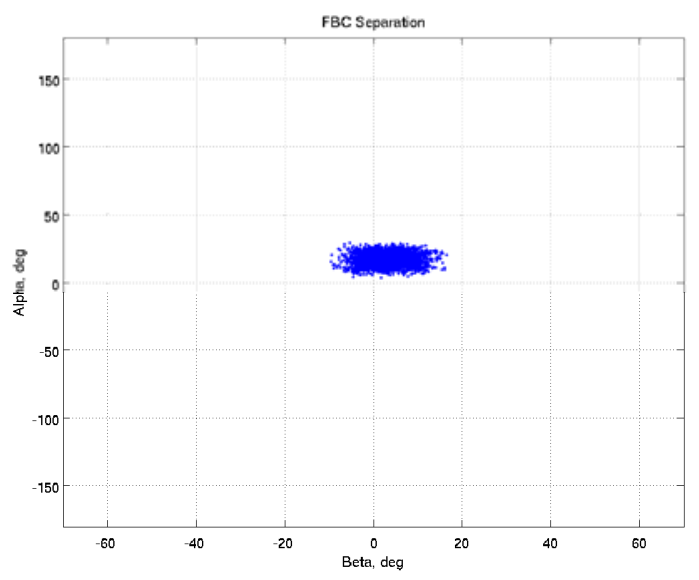

Figure 19. CM aerodynamic angles at FBC jettison for 8,000ft abort Monte Carlo.

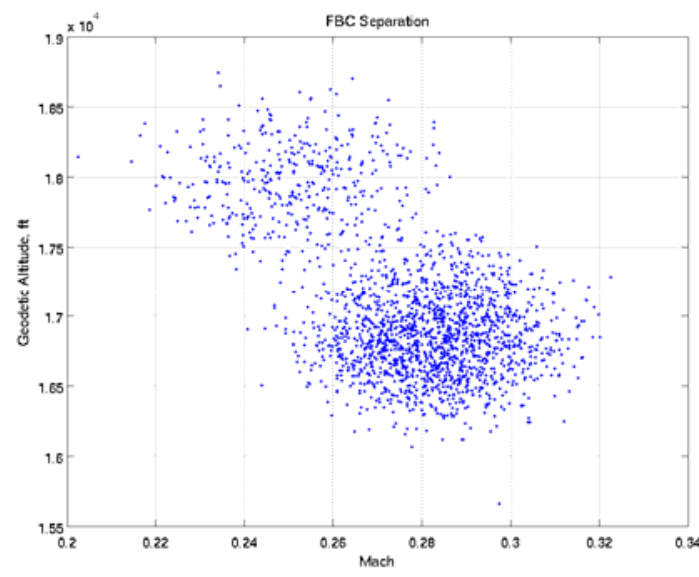

Figure 20. CM mach and altitude at FBC jettison for 8,000ft abort Monte Carlo.

Figure 19 shows the aerodynamic attitude at the FBC jettison event one second after LAS jettison; the CM attitude has changed to the trim angle of attack at $30^{\circ}$. The separation aerodynamics and non-equal forces from the separation gas-pistons has some influence as well. Figure 20 shows the trajectory characteristics of mach and altitude at the FBC jettison event. There are two clouds of points due to the break point in the controller at $8000 \mathrm{ft}$. In this version of the flight controller the pitch maneuver is changed to a much smaller pitch maneuver right at 8000 $\mathrm{ft}$. The cases that initiate just above $8000 \mathrm{ft}$ are at a altitude at $\mathrm{FBC}$ separation due to the smaller pitch maneuver. 


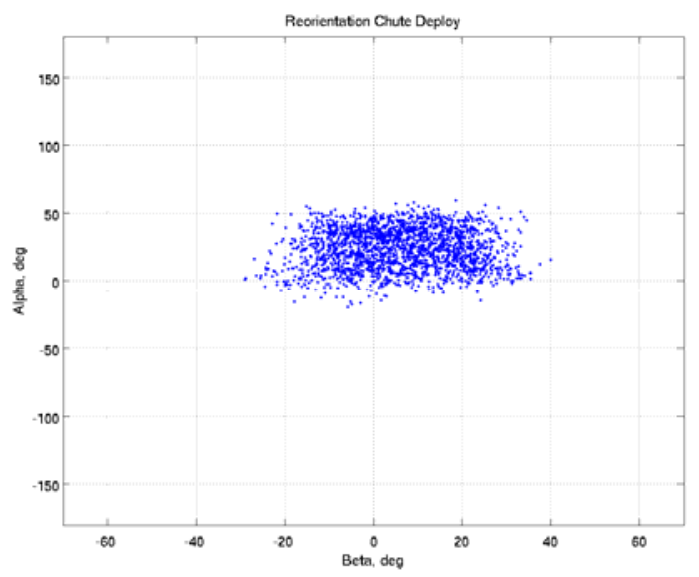

Figure 21. CM aerodynamic angles at reorientation parachute deployment for 8,000ft abort Monte Carlo.

Figure 21 shows the aerodynamic attitude one second later at reorientation parachute deployment. The CM attitude has scattered more at this point. Figure 22 shows the mach and altitude at reorientation parachute deployment; note that the FBC jettison occurs while the vehicle is still ascending and the reorientation parachute deployment occurs at a higher altitude but lower Mach number.

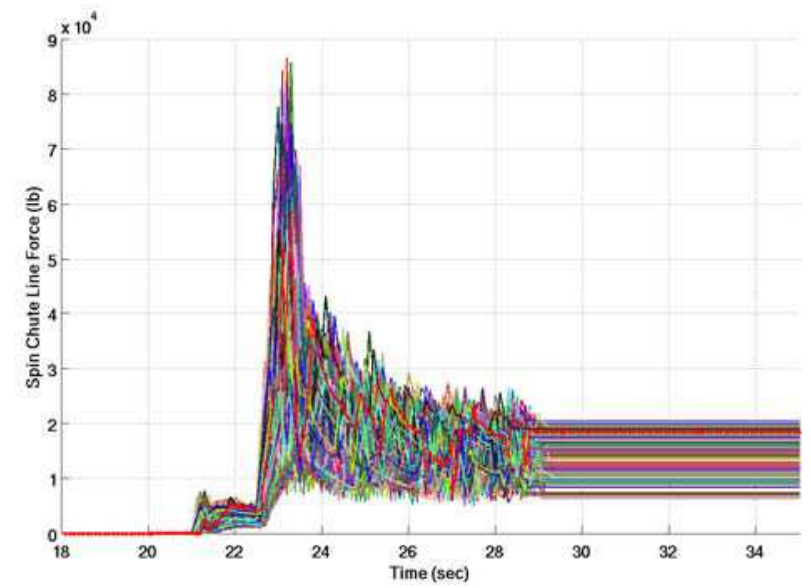

Figure 23. Reorientation parachute line loads for 8,000ft abort Monte Carlo.

Figures 24 and 24 show the line loads for the reorientation parachute. No limit load for the reorientation parachute was designated during the period of study.
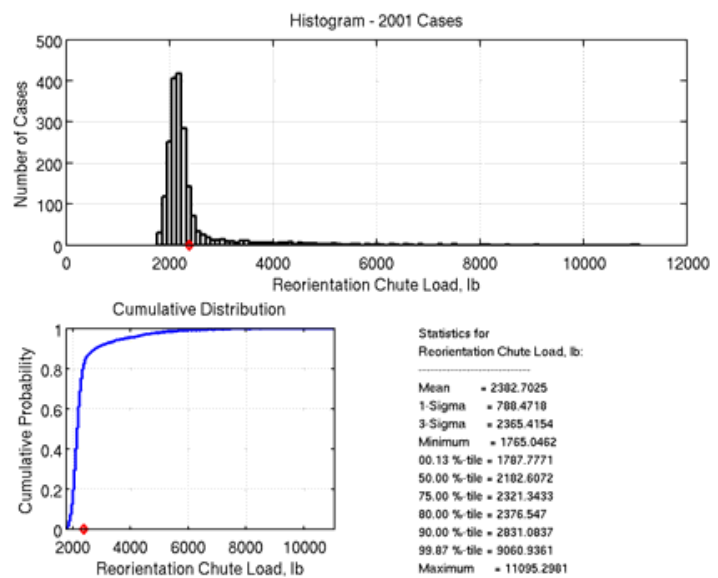

Figure 24. Reorientation parachute maximum line load statistics for 8,000ft abort Monte Carlo. 


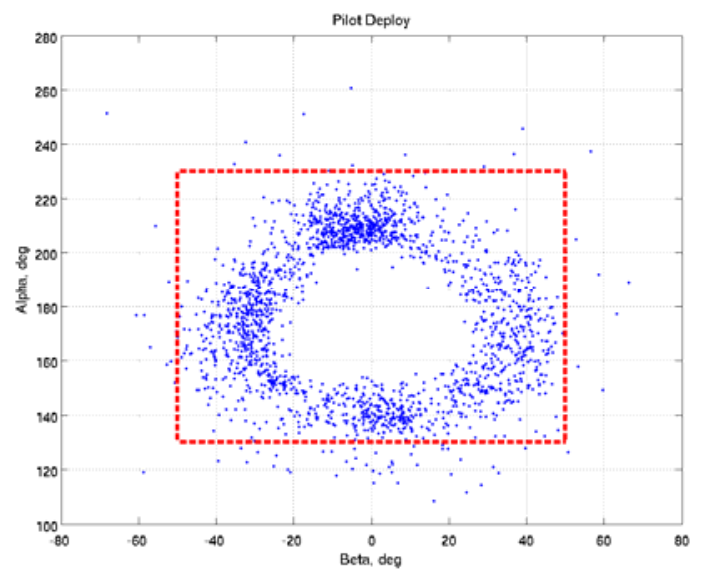

Figure 25. CM attitude at pilot parachute deployment for $\mathbf{8 , 0 0 0 f t}$ abort Monte Carlo.
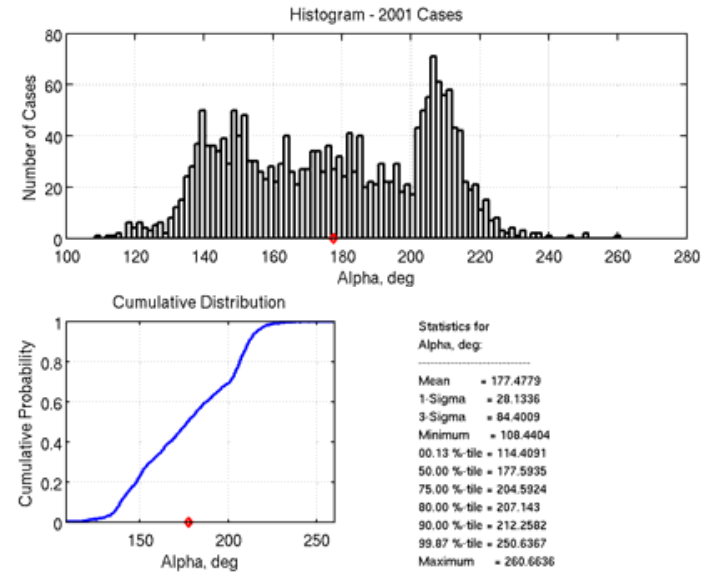

Figure 26. CM attitude statistics at pilot parachute deployment for $\mathbf{8 , 0 0 0 f t}$ abort Monte Carlo.

The pilot chute deployment aerodynamic angles, Figures 25 and 26 are driven by the smart release algorithm, which seeks out the minimum angular rates, subject to a constraint of a percentage of the average angular rates, and releases the parachute at that point. The minimum angular rates occur at the end of the oscillation, the place of maximum angle. In this context, the circular shape of the plot is understandable.

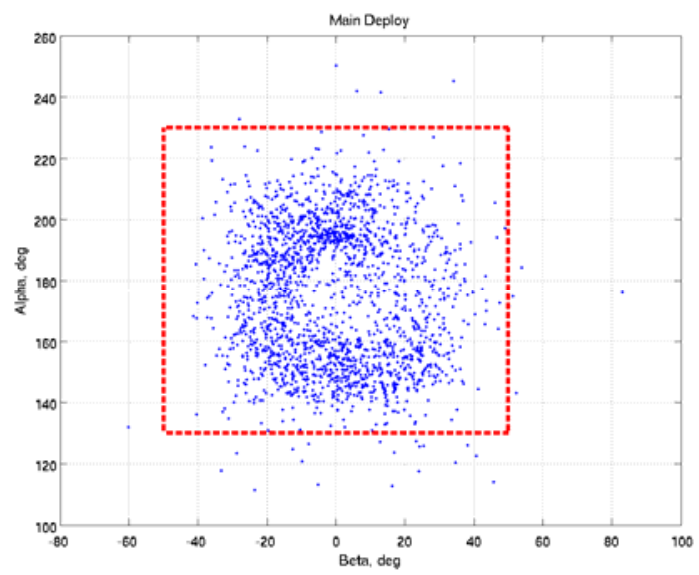

Figure 27. CM attitude at main parachute deployment for 8,000ft abort Monte Carlo.
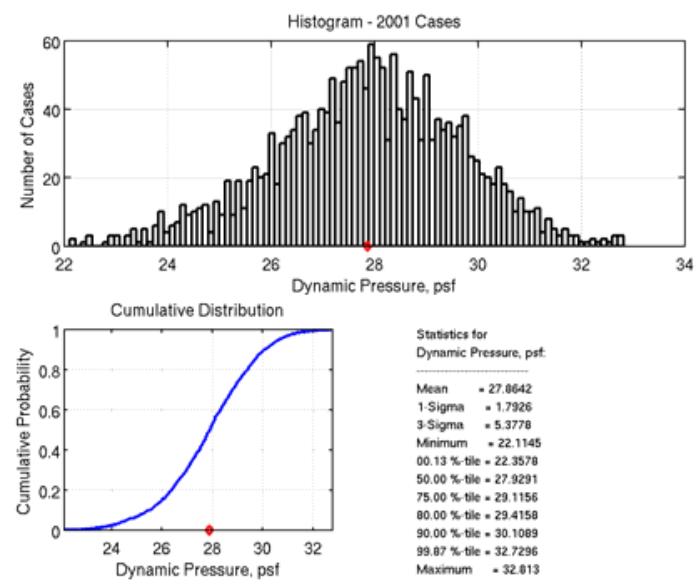

Figure 28. CM attitude statistics at main parachute deployment for $\mathbf{8 , 0 0 0 f t}$ abort Monte Carlo.

Figure 27 shows the CM aerodynamic attitude at main parachute deployment. The circular pattern is still visible, due to the smart release algorithm, but the vehicle has oscillated some in the time during the pilot parachute line deployment. Figure 28 shows the low dynamic pressure at main parachute deployment. 


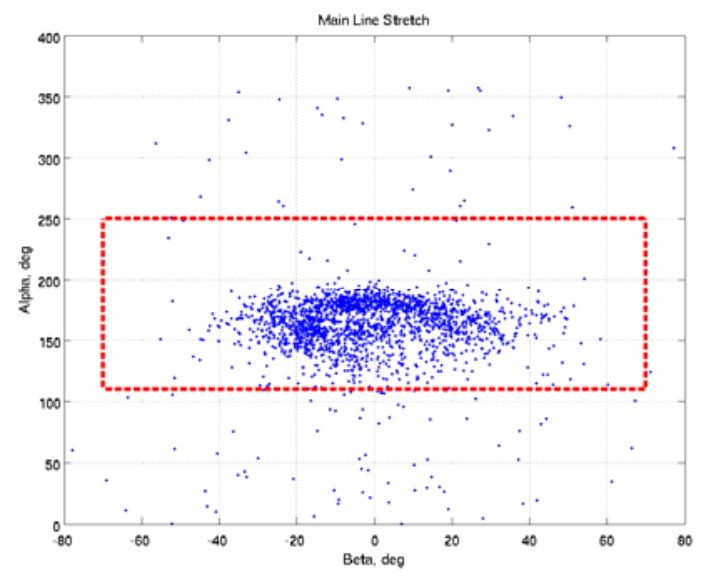

Figure 29. CM attitude at main parachute line stretch for 8,000ft abort Monte Carlo.
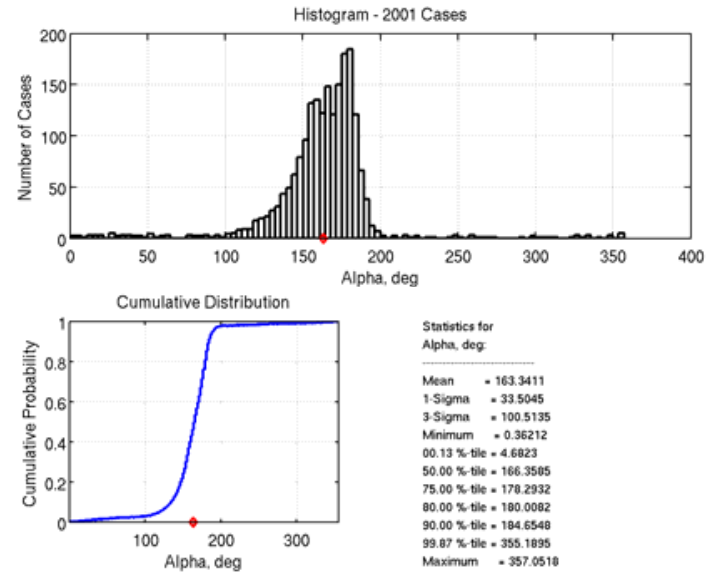

Figure 30. CM attitude statistics at main parachute line stretch for $\mathbf{8 , 0 0 0 f t}$ abort Monte Carlo.

A short time afterwards the vehicle reaches the main parachute line stretch condition. Figures 29 and 30 show the vehicle has generally reached an acceptable attitude during the pilot parachute deployment. However, as shown in Figure 14, the time history reveals that many cases do flip during that period.
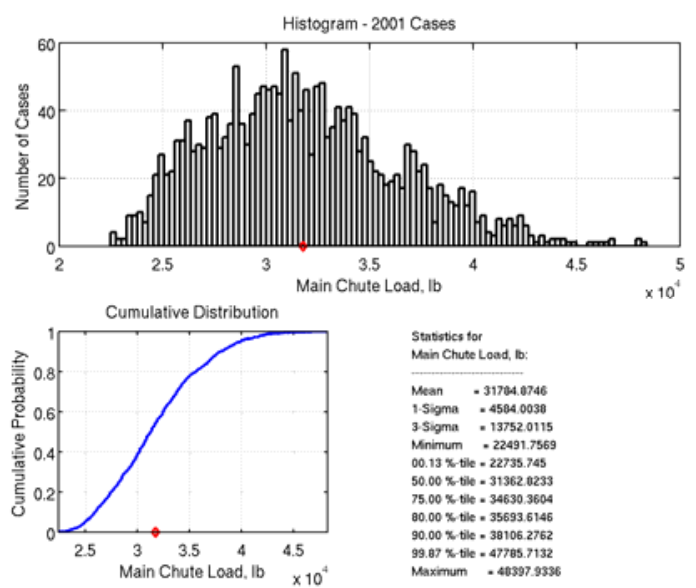

Figure 31. Main parachute line loads for $8,000 \mathrm{ft}$ abort Monte Carlo.
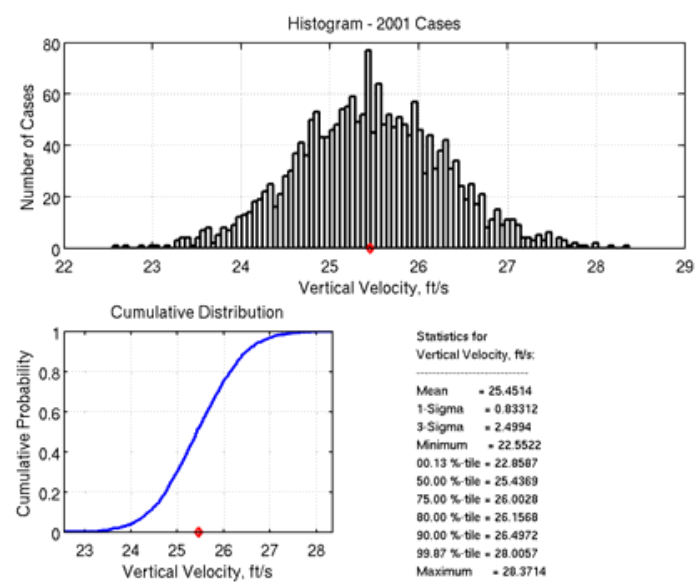

Figure 32. CM vertical velocity at touchdown for 8,000ft abort Monte Carlo.

Figure 31 shows the maximum RSS of the main parachute line loads; due to the low dynamic pressure, all line loads are well below the limit load. Figure 32 shows the vertical velocity at touchdown; all of the cases are below the limit of $33 \mathrm{ft} / \mathrm{s}$. Figure 33 shows a map of all the landing locations. Obviously some of the cases are landing inland. This is due to the winds; Figure 13 shows the main parachutes are fully open at a high altitude, giving the winds plenty of opportunity to push the vehicle inland. 


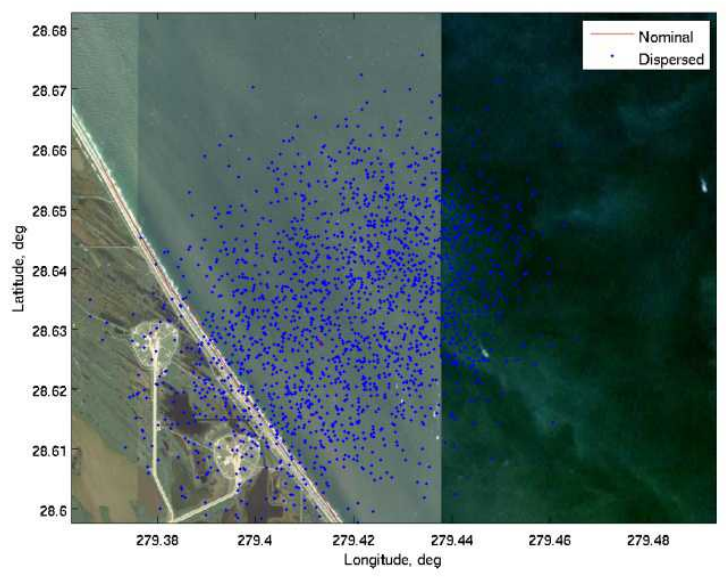

Figure 33. Map of CM landing locations for 8,000ft abort Monte Carlo.

\section{Mach 1.0 Abort}

LAV abort simulations (POST2) are initiated from the TD6-H CLV trajectories (Light/Fast, August, Lunar mission, Open launch window) when the CLV reaches Mach 1.0. This Monte Carlo set consists of 500 cases from abort initiation to reorientation parachute line stretch. These cases are evaluated due to the aerodynamics associated with the Mach 1.0 region where separation of the Launch Abort Tower from the CM is expected to be the most difficult. No parachute failures are evaluated for these cases.

Figure 34 shows the lateral separation distance between the LAT and the CM while they are in close proximity for the Mach 1.0 abort Monte Carlo. It can be seen that the lateral separation is small, on the order of one tenth of a foot, during the first foot of axial separation distance, which is important for minimizing recontact between the two bodies. The cases in red shown in Figure 34 represent those cases that experienced tumbling before the tower is jettisoned. Some tumbling is expected due to the dynamics of this region.

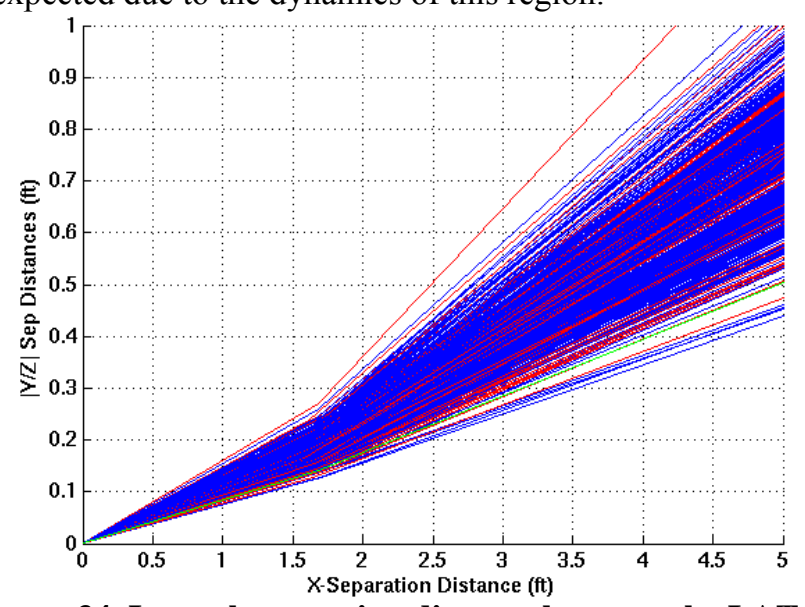

Figure 34. Lateral separation distance between the LAT and $\mathrm{CM}$ while they are in close proximity for Mach 1.0 abort Monte Carlo.

The total separation distance between the LAT and the CM while they are in close proximity is shown in Figure 35 for this Monte Carlo. The tower shows good separation in the first second after jettison. Many cases show that later in the trajectory the tower and the CM once again come in close proximity. This is believed to be partially due to the skewing of the aerodynamic database separation coordinate frame discussed previously. 


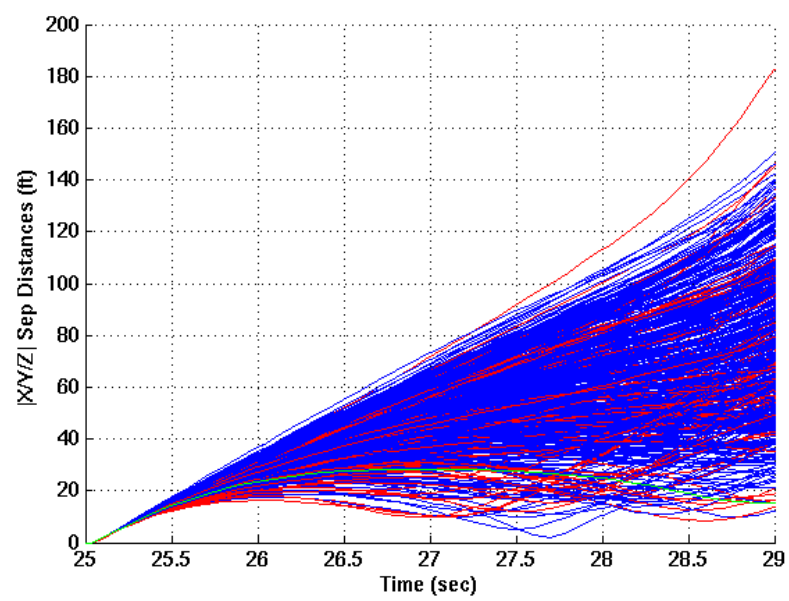

Figure 35. Total separation distance between the LAT and CM while they are in close proximity for Mach 1.0 abort Monte Carlo.

Table 6. Percentage failures for 500 case Mach 1.0 abort Monte Carlo terminated at drogue parachute line stretch

\begin{tabular}{|l|c|}
\hline \multicolumn{1}{|c|}{ Metric } & Failures \\
\hline Tumbling before tower jettison & $17 \%$ \\
\hline Q- $\alpha_{\text {total }}$ & $0.8 \%$ \\
\hline $\begin{array}{l}\text { Separation from the CLV less than 175 ft at } \\
\text { time greater than 3 seconds }\end{array}$ & $4.6 \%$ \\
\hline
\end{tabular}

The numbers of failures for several metrics are shown for the 500 case Mach 1.0 abort Monte Carlo. Since the simulations were terminated when the drogue parachutes reached line stretch only those metrics that occurred before this time are presented. These numbers are presented for reference and were not the main reason for performing this analysis.

\section{Conclusion}

This study investigated the RLAS LAV abort parachute architecture, applied specifically to pad, low altitude and Mach 1 aborts for the operational vehicle, to address concerns with the current parachute architecture. It was shown that the 8,000ft LAV aborts can be pushed back inland by the wind, but proper tailoring of the pitch maneuver could yield improvement. The RLAS configuration was shown to provide better close proximity separation between the $\mathrm{CM}$ and LAT post tower jettison than the straight to mains approach. Although this study verified that the RLAS architecture is realistic, there are a few problems that could not be overlooked. One of the major concerns was the potential flip over of the $\mathrm{CM}$ after reorientation parachute release. Another problem for this configuration was the concern that using a triple bridle for the reorientation parachute would cause parachute packing and potentially recontact concerns. Future study would include optimization of the LAS initial pitch maneuver and application of DOLILU (Day of Launch I-Load Update) pitch profiles.

\section{References}

${ }^{1}$ CEV Aerodynamic Database Application Programming Interface Users' Guide, Revision 0.53.0, May 2009.

${ }^{2}$ EG-CAP-06-37, "Formulation of the Orion Aerodynamic Database," Revision 0.53, 1 May, 2009.

${ }^{3}$ CEV-SA-09-023, "Preliminary Assessment of Production Vehicle Pad Abort JM Plume Interference with CPAS Drogue Parachutes," 29 April, 2009.

${ }^{4}$ Rivellini, Tommaso, “Abort Mortar RLAS revA.ppt”, August 2009

${ }^{5}$ Email correspondence from Jim Lanzi, 25 August, 2009

${ }^{6}$ JSC 64106 FD PA1 dCDR Volume 2 May 2008.pdf, May 2008

${ }^{7}$ Thruster_PropelledLAS_sep_dyn_aero_v3_MHughes_20090812.pptx, Mike Hughes, 12 August, 2009. 